\title{
Comportamiento del lenguaje de líderes políticos venezolanos en el uso de Twitter*
}

\author{
Language Behavior of the Venezuelan Political Leaders when Using Twitter \\ Comportamento da linguagem de líderes políticos venezuelanos no uso de Twitter
}

\author{
Pedro David Aguillón Vale a \\ Universidad de Zulia, Venezuela \\ paguillón811@gmail.com \\ ORCID: http://orcid.org/0000-0002-9287-9950 \\ Jellicy Narváez Serra \\ Universidad de Zulia, Venezuela \\ ORCID: http://orcid.org/0000-0002-3732-3263
}

Fecha de recepción: 30 Junio 2018

\section{Resumen:}

Este artículo analiza, desde una perspectiva lingüístico-discursiva, el comportamiento del lenguaje que asumieron líderes políticos venezolanos en la producción de mensajes en sus cuentas de Twitter. Se analizaron 356 tuits a partir del enfoque semántico y pragmático y la perspectiva sociocognitiva del análisis crítico. Los resultados revelaron: a) el referendo revocatorio contra el presidente Nicolás Maduro y Patria constituyeron los temas más recurrentes y b) la profusión de lexías negativas y acciones lingüísticas de aseveración e insultos marcaron la ofensiva verbal que definió el discurso político. Se concluye que la intención comunicativa de los líderes estuvo más enfocada a acrecentar la confrontación discursiva que a promover un verdadero diálogo de paz en el contexto político venezolano.

Palabras clave: comportamiento del lenguaje, perspectiva lingüístico-discursiva, enfoque semántico y pragmático, enfoque sociocognitivo, Twitter, líderes políticos venezolanos.

\section{Abstract:}

This article analyzes, from a linguistic-discursive perspective, the language behavior by the Venezuelan political leaders when producing messages in their Twitter accounts. Three hundred and fifty-six tweets were analyzed under a semantic and pragmatic approach and from the sociocognitive perspective of the critical discourse analysis. The results showed that: a) the revocatory referendum against President Nicolás Maduro and his Patria Plan were the most recurring topics, and b) the profusion of negative lexical units as well as linguistic actions of assertion and insult provided the standard of verbal offense defining the political discourse. It is concluded that the communicative intention of the leaders focused mostly on increasing the discursive contention rather than promoting a true peace dialogue in the Venezuelan political context.

Keywords: language behavior, linguistic-discursive perspective, semantic and pragmatic approach, sociocognitive approach, Twitter, Venezuelan political leaders.

\section{Resumo:}

Este artigo analisa, desde uma perspectiva linguístico-discursiva, o comportamento linguístico que assumiram líderes políticos venezuelanos na produção de mensagens nas suas contas de Twitter. Analisaram-se 356 tweets a partir do enfoque semântico e pragmático e a perspectiva sóciocognitiva da análise crítica. Os resultados revelaram: a) o referendo revogatório contra o presidente Nicolás Maduro e Pátria constituíram os temas mais recorrentes e b) a profusão de lexias negativas e ações linguísticas de asseveração e insultos marcaram a ofensiva verbal que definiu o discurso político. Conclui-se que a intenção comunicativa dos líderes esteve mais focada em acrescentar a confrontação discursiva do que a promover um verdadeiro diálogo de paz no contexto político venezuelano. Palavras-chave: comportamento da linguagem, perspectiva linguístico-discursiva, enfoque semântico e pragmático, enfoque sóciocognitivo, Twitter, líderes políticos venezuelanos.

Notas de autor: 


\section{Introducción}

Tras el crecimiento exponencial que durante los últimos años han alcanzado las redes sociales, Twitter se presenta entre ellas como una plataforma comunicacional digital, donde converge un sinfín de usuarios anónimos y grupos sociales que, a través de sus perfiles, comparten intereses comunes y contenidos informativos. Visto de este modo, Twitter representa un nuevo medio de comunicación por cuanto ha generado un código comunicativo y unas pautas de interacción propias (Lara, 2012).

Los mensajes que se producen desde esta novedosa herramienta de carácter masivo, llaman la atención de los diversos enfoques y disciplinas de las ciencias del lenguaje y la comunicación, pues los tuits, como actividad discursiva que se producen desde Twitter, implican el manejo del lenguaje como una práctica social contextualizada en uso. De allí, el interés del análisis del discurso al estudiar el decir y el hacer subyacente en la intencionalidad comunicativa que expresan los interlocutores, quienes son los que determinan el contenido y las formas de los mensajes.

Las características y funciones básicas que se le atribuyen a Twitter desde su creación en 2006, se debe, entre otras cosas, a la operatividad que experimentan los usuarios en el manejo de este servicio de microblogging. Martínez Martín (2012), Lara (2012), Mancera Rueda y Pano Alamán (2013) y Ventura (2016) destacan que esta herramienta, además del servicio gratuito que ofrece, permite la publicación y lectura de mensajes de textos en línea de hasta 140 caracteres, compartir fotos, videos y sonidos y beneficiarse de la brevedad, fluidez y rapidez para la emisión y recepción de mensajes en tiempo real y de la inmediatez y conexión en directo con el ciudadano.

En virtud de estas condiciones y para estar a la par con los avances tecnológicos que demanda el mundo moderno, se ha evidenciado que los actores políticos están potenciando cada día más el uso de Twitter como herramienta virtual para hacer política: discutir problemas sociales, activar el debate público, compartir información y de modo inmediato: "está al servicio de otras funciones más allá de la expresión personal: publicitar las acciones de gobierno, legitimarse ante los adversarios y reforzar la adhesión” (Mazzuchino, 2017, p. 70).

Los mensajes escritos de los actores políticos en las cuentas oficiales de Twitter, pueden considerarse discursos políticos por cuanto sus textos se producen en una situación comunicativa protagonizada por ciudadanos que lideran una organización, partido político o ente gubernamental, que buscan, mediante el uso de diversas estrategias lingüísticas y discursivas, captar el mayor número de seguidores y, sobre todo, influir de manera ideológica en sus conductas, opiniones y actitudes. En fin, desde esta perspectiva, el uso de Twitter se concibe como una plataforma política que mantiene activa la interacción de comunicación entre actores políticos y ciudadanos, sin intermediarios y sin la censura que imponen los medios masivos de comunicación; de hecho, a mayor número de seguidores que registre el líder político, mayor también será su incidencia en determinados temas que marcan la opinión en la esfera pública.

Nos encuadramos en el escenario actual de Venezuela, caracterizado por una profunda crisis política y socioeconómica, evento que en los últimos años ha desencadenado la protesta colectiva civil y la confrontación verbal entre la dirigencia de las dos tendencias políticas que mantienen la lucha por la gobernabilidad y el poder: oposición y oficialismo. Bajo estas circunstancias, muchas han sido las alternativas que se han planteado con el propósito de disminuir el tono de agresividad en el lenguaje utilizado en el debate político, mitigar los grados de conflictividad y garantizar la convivencia democrática nacional. De allí que, desde el Gobierno nacional, se ha propuesto un diálogo de paz que involucre a todos los sectores y fuerzas políticas del país, no obstante, estos esfuerzos de negociación por la reconciliación nacional en Venezuela hasta ahora no se han podido concretar.

En este contexto de polarización política, donde los actores de ambos sectores expresan en esta herramienta comunicacional sus propias percepciones acerca de la realidad venezolana, con mayor grado de libertad y sin la censura controlada que imponen los medios masivos tradicionales de información, los tuits políticos se 
manifiestan con enunciados subyacentes, dotados de sentidos y significancias ideológicas en toda su plenitud. Por consiguiente, el propósito que se plantea este estudio es analizar, desde una perspectiva lingüísticodiscursiva, el comportamiento del lenguaje que asumen líderes políticos venezolanos en la producción de mensajes en sus cuentas de Twitter como canal de comunicación masiva.

Para el análisis, se escogió una muestra representativa de textos tomados de las cuentas oficiales de Twitter de los líderes políticos venezolanos seleccionados, durante los meses de julio a septiembre de 2016. El periodista Romero-Castillo resalta en el boletín DW Made for minds (2016), algunos de los aspectos que definieron la crisis venezolana durante este trimestre: el peligro de la oposición para revocar el mandato de Maduro, la apuesta del Gobierno al diálogo y promoción de pactos con otros países para elevar el precio del petróleo, la decisión del Consejo Nacional Electoral (CNE) sobre las fechas y condiciones para la segunda recolección de firmas a favor del referendo revocatorio, la concentración convocada por la oposición para el 1. ${ }^{\circ}$ de septiembre llamada “Toma de Caracas” y las acusaciones del Gobierno contra Estados Unidos.

La intención del trabajo que se presenta es indagar, mediante la aplicación de los esquemas de análisis pertenecientes al enfoque semántico y pragmático y el análisis sociocognitivo, cómo estos y otros eventos difundidos a través de los medios masivos de información durante el periodo seleccionado, adoptan la forma discursiva, se contextualizan y amplifican de manera paralela en las agendas públicas promovidas por la dirigencia política desde sus tuits. Por consiguiente, como lo plantea Ventura (2016), la mediatización del discurso político en las redes sociales reaviva el debate en torno a las transformaciones que estas nuevas prácticas discursivas introducen en las formas de hacer política.

\section{Enfoque teórico-metodológico}

\section{La perspectiva lingüístico-discursiva}

Este estudio está basado en la aplicación de esquemas teórico-metodológicos pertenecientes a las dos perspectivas de análisis enmarcadas en la lingüística-discursiva. La primera se focaliza en el enfoque semántico y pragmático (Molero de Cabeza y Cabeza, 2006, 2009) y la segunda hace mención al análisis crítico del discurso (ACD), que permitirá abordar las concepciones del análisis sociocognitivo del discurso tomados de Van Dijk (1999, 2008, 2016).

El enfoque semántico y pragmático tiene su base en los principios de la semántica lingüística de Pottier (1992), a partir de los cuales se configura. De acuerdo con Molero de Cabeza y Cabeza (2009, p. 20), lo semántico "está referido a la información contenida en el discurso, es decir, a los sentidos que transmite a los lectores o receptores, lo que se dice (o no se dice o calla) y la forma cómo se dice”. Esto explica las transformaciones que adquiere el significado a partir del contexto en el que se circunscribe el discurso. Por su parte, lo pragmático ofrece una visión discursiva desde la situación donde se enmarca el evento comunicativo. Este componente "tiene que ver con los participantes, con el contexto o situación en la que se produce el discurso y con los actos de habla” (p. 20).

Este enfoque comprende cuatro niveles metodológicamente necesarios para el recorrido del emisor. De acuerdo con Molero de Cabeza y Cabeza (2006, 2009), son: el nivel referencial que construye o reconstruye la complejidad del mundo real o imaginario; el nivel conceptual que abarca el propósito o la intención de comunicación subyacente en el querer decir del emisor; las formas lingüísticas que pone en práctica el hablante en la producción de sus mensajes, constituye el nivel lingüístico; en tanto que, en el nivel discursivo, se presenta el producto o hecho observable que tiene frente a sí el analista.

Por su parte, el ACD constituye una postura dentro del análisis del discurso que, desde una perspectiva crítica, estudia las situaciones concretas de interacción social cuando adoptan una forma lingüística, es decir, estudia el uso del lenguaje en las relaciones sociales. En el presente estudio, el análisis se aplicará a partir de 
la perspectiva sociocognitiva de Van Dijk (1999, 2008, 2016), cuyo basamento radica en que la cognición social opera siempre como una interfaz mediadora entre las estructuras del discurso y las estructuras sociales (1999). Este autor considera que "las estructuras del discurso y las estructuras sociales son de naturaleza distinta y solo pueden estar relacionadas a través de representaciones mentales de los usuarios del lenguaje como individuos y como miembros sociales" (2016, p. 139). Aunado a ello y considerando la naturaleza de este trabajo, es pertinente señalar que el ACD se focaliza en la compleja interacción de los grupos sociales, disidentes y opositores y sus discursos dentro de la sociedad (1999).

\section{Las categorías del análisis discursivo}

Atendiendo estas concepciones teóricas, es importante precisar la metodología que se va a seguir para el análisis de los mensajes (tuits) escritos en Twitter por los líderes políticos. En primera instancia, se ubican los perfiles que caracterizan sus cuentas de Twitter, para así tener los aspectos referenciales acerca de las posturas ideológicas que asumen los actores seleccionados en el contexto político venezolano; posteriormente, se identifican los temas o tópicos que propician los líderes políticos en la producción de sus mensajes, puesto que es aquí donde se manifiesta su intencionalidad comunicativa y se pone en evidencia la forma de cómo conceptualizan su propia visión de los diversos eventos.

Para Molero de Cabeza y Cabeza (2009), el enfoque semántico y pragmático considera que los temas o ejes temáticos desempeñan un papel fundamental en la comunicación y en la interacción discursiva; estos constituyen un esfuerzo de abstracción para reducir el discurso total a esquemas más globales y generalizantes. Una postura similar tiene Van Dijk $(1999,2008)$ para quien los temas constituyen la información más importante en el texto, pues organizan los significados y la coherencia global, y pueden ser reconocidos por el hablante mediante una organización explícita de los modelos mentales y de la formación del conocimiento general.

Una vez precisados los temas o ejes temáticos, el siguiente paso que observa es el funcionamiento del léxico. Para ello, se levantaron los campos léxico-semánticos con el repertorio de palabras que surgen de las prácticas socioculturales y discursivas, donde se enmarcan los mensajes de los dirigentes políticos. En este sentido, el nivel lingüístico otorga especial importancia al léxico, puesto que "a través del léxico se pueden aflorar o salir a la superficie las opiniones e ideologías ocultas" (Molero de Cabeza y Cabeza, 2009, p. 67). Desde la perspectiva de Van Dijk (1999, p. 259), el estudio del léxico "es un importante medio de expresión ideológica en el discurso", ya que el simple hecho de explicar todas las implicaciones de las palabras utilizadas en un discurso provee un amplio conjunto de significados ideológicos.

Del mismo modo, en el análisis se pone de manifiesto el enfoque pragmático mediante el significado del lenguaje en uso, pues se hace necesario construir el sentido a partir de la intención comunicativa que subyace en los tuits, mediante el estudio de los actos de habla. Estos se definen según las condiciones sociales de los participantes, tales como sus creencias, deseos, intenciones, evaluaciones y objetivos, con implicaciones sociales (Van Dijk, 1999). Las aseveraciones, amenazas, promesas, insultos, órdenes y hacer un juramento constituyen ejemplos de actos de habla o actos lingüísticos.

No obstante, el análisis de los actos de habla que se aplica en este estudio sigue la tipología de los actos de habla propuesta por Searle (1976 citado por Calsamiglia y Tusón, 1999), que los agrupa en cinco clases: asertivos, directivos, compromisorios, expresivos y declarativos. Todas las categorías de análisis propuestas constituyen, para Van Dijk (2016), estructuras discursivas y sociocognitivas que funcionan como tal en la interacción comunicativa. 


\section{Objetivos del estudio}

El objetivo general del estudio se focaliza en analizar el comportamiento del lenguaje de los líderes políticos venezolanos en el uso de la red social Twitter. Como objetivos específicos se plantean: a) examinar los perfiles que identifican a los actores políticos venezolanos en sus cuentas de Twitter; b) identificar los temas o ejes temáticos que más propician los actores políticos en sus mensajes de Twitter; c) describir el estilo lexical mediante los campos léxico-semánticos, utilizados para resaltar o atenuar el comportamiento discursivo de los líderes políticos y d) precisar las tipologías de las acciones lingüísticas expresadas en los mensajes (tuits).

\section{Corpus del análisis}

El corpus estuvo conformado por los mensajes (tuits) escritos de manera directa en sus cuentas de Twitter por líderes políticos venezolanos, para cuya escogencia se establecieron los siguientes criterios: a) tres representantes por cada tendencia política, b) mayor número de seguidores en sus cuentas públicas de Twitter y c) estrecha vinculación con el Alto Gobierno y la Mesa de la Unidad Democrática (MUD). Bajo estas premisas, los seis líderes seleccionados fueron: por el sector oficialista y vinculación con el Gobierno, Nicolás Maduro, Diosdado Cabello y Jorge Arreaza; mientras que por la coalición opositora al Gobierno, María Corina Machado, Henrique Capriles y Henry Ramos Allup. Por otro lado, los tuits fueron recabados durante el tercer trimestre de 2016 (julio, agosto y septiembre), para lo cual se aplicó la estrategia de la semana tipo, donde, de forma aleatoria e intencional, se escogieron siete días a la semana por cada mes, quedando especificado de la siguiente manera: julio (lunes 25, martes 5, miércoles 13, jueves 21, viernes 1 , sábado 9 y domingo 31); agosto (lunes 29, martes 30, miércoles 10, jueves 25, viernes 19 , sábado 6 y domingo 14) y septiembre (lunes 19, martes 13, miércoles 7 , jueves 1, viernes 30, sábado 24 y domingo 25). Todo ello permitió recopilar un corpus total de 356 mensajes directos o tuits propios, cuyo texto escrito se constituyó en la unidad de análisis, quedando excluidos los mensajes retuiteados, las fotografías y los videos.

\section{Resultados del análisis}

\section{Características de los perfiles de líderes políticos venezolanos}

La primera categoría que se considera son los perfiles públicos oficiales que identifican las cuentas de Twitter de los actores políticos escogidos, puesto que estas características aportan aspectos referenciales relevantes acerca del papel que desempeñan estas figuras dentro del contexto político venezolano.

Para el estudio de los perfiles de los usuarios, se siguió la estructura que ofrece Twitter, conformada por dos bloques y una identificatoria. En el bloque de la izquierda, aparecen el nombre, la imagen, la biografía y algunos datos interesantes como los tuits enviados, número de seguidos, los seguidores y los temas globales (trending topics). En el de la derecha, denominado Cronología o Timeline, se publican los tuits que llegan en secuencia y se van almacenando en la bandeja; estos se muestran públicamente en el perfil del usuario y en la cronología de sus seguidores. En cuanto a la identificatoria, se presentan fotografías y una breve descripción biográfica, que identifican su perfil personal en la red.

En el caso de los dirigentes políticos, el manejo de estos aspectos es fundamental, pues como figuras públicas, sus perfiles en Twitter delatan la imagen que desean proyectar de sí mismos o de su quehacer político al momento de interactuar con sus seguidores; al mismo tiempo, la conformación de su imagen les permite mantener una opción atractiva para poder acercarse a otros ciudadanos y poder captar el mayor número de ellos. 
Al examinar los renglones más importantes, la tabla 1 muestra una visión general acerca de los perfiles que identifican las cuentas de Twitter de seis líderes políticos. Entre los aspectos que se pueden resaltar, se tiene que Henrique Capriles es el dirigente opositor que mayor tiempo tiene en esta red, el único que no hace aporte de su descripción o la actividad política que desempeña, pero sí se identifica con datos en su biografía (fecha de nacimiento) y el que utiliza la etiqueta \#YoSoyVenezolano. El uso de esta estrategia permite que tanto el sistema como el usuario lo identifiquen de manera más rápida.

TABLA 1

Perfiles de los actores políticos venezolanos en Twitter

\begin{tabular}{|c|c|c|c|c|c|c|}
\hline & \multicolumn{3}{|c|}{ Oposición } & \multicolumn{3}{|c|}{ Oficialismo } \\
\hline Perfil & $\begin{array}{l}\text { Maria C. } \\
\text { Machado }\end{array}$ & $\begin{array}{c}\text { Henrique Capriles } \\
\text { R. }\end{array}$ & Henry Ramos A. & Nicolás Maduro M. & Diosdado Cabello & Jorge Arreaza \\
\hline Cuenta & (a) MariaCorinaYa & @hcapriles & @hramosallup & @Nicolasmaduro & @dcabellor & @jaarreaza \\
\hline Ubicación & Venezuela & Venezuela & Venezuela & Venezuela & Venezuela & Venezuela \\
\hline $\begin{array}{l}\text { Descripción } \\
\text { personal/o } \\
\text { actividad } \\
\text { Política }\end{array}$ & $\begin{array}{l}\text { - Coordinadora de } \\
\text { Vente Venezuela }\end{array}$ & -- & $\begin{array}{l}\text {-Secretario } \\
\text { General } \\
\text { Nacional de } \\
\text { Acción } \\
\text { Democrática } \\
\text { •Vicepresidente } \\
\text { de la } \\
\text { Internacional } \\
\text { Socialista } \\
\text {-Diputado a la } \\
\text { Asamblea } \\
\text { Nacional }\end{array}$ & $\begin{array}{l}\text { - Presidente de la } \\
\text { República } \\
\text { Bolivariana de } \\
\text { Venezuela } \\
\text { - Hijo de Chávez }\end{array}$ & $\begin{array}{l}\text { - Venezolano, } \\
\text { Bolivariano, } \\
\text { revolucionario y } \\
\text { chavista radical }\end{array}$ & $\begin{array}{l}\text { - Militante, } \\
\text { Socialista- } \\
\text { Chavista- } \\
\text { Bolivariano } \\
\text { •Vicepresidente } \\
\text { para el Desarrollo } \\
\text { Social y la } \\
\text { Revolución de las } \\
\text { Misiones }\end{array}$ \\
\hline Biografia & -- & Nació el 11 de julio & -- & -. & -- & -- \\
\hline $\begin{array}{l}\text { Fecha de } \\
\text { Creación }\end{array}$ & Enero, 2010 & Junio, 2009 & Octubre, 2010 & Marzo, 2013 & Marzo, 2010 & Abril, 2010 \\
\hline Seguidores & $4,35 \mathrm{M}$ & $7,3 \mathrm{M}$ & $1,74 \mathrm{M}$ & $3,3 \mathrm{M}$ & $2,15 \mathrm{M}$ & $1,49 \mathrm{M}$ \\
\hline Siguiendo & 4170 & 1939 & 192 & 124 & $23,1 \mathrm{~K}$ & 6461 \\
\hline Enlaces & mariacorina.com & $\begin{array}{l}\text { Facebook.com/ } \\
\text { HenriqueCapriles }\end{array}$ & $\begin{array}{l}\text { Instagram.com/ } \\
\text { Hramosallup }\end{array}$ & $\begin{array}{c}\text { nicolasmaduro.org. } \\
\text { ve }\end{array}$ & -- & $\begin{array}{l}\text { Blog.jaarreaza.org. } \\
\text { ve }\end{array}$ \\
\hline $\begin{array}{l}\text { Cuenta } \\
\text { Verificada }\end{array}$ & $\checkmark$ & $\checkmark$ & $\checkmark$ & $\checkmark$ & -. & $\checkmark$ \\
\hline $\begin{array}{l}\text { Etiquetas/ } \\
\text { Otros aspectos }\end{array}$ & .. & \#YoSoyVenezolano & -. & $\begin{array}{l}\text { Construyendo la } \\
\text { Patria con eficiencia } \\
\text { revolucionaria }\end{array}$ & $\begin{array}{l}\text { En la lucha por la } \\
\text { construcción del } \\
\text { Socialismo }\end{array}$ & ¡Patriota! \\
\hline
\end{tabular}

Nota: Datos vigentes para tercer trimestre de 2016 (julio, agosto y septiembre).

Con respecto a los funcionarios del Alto Gobierno, Nicolás Maduro es el que registra, por la tendencia oficialista, el menor tiempo de actividad en Twitter. Llama la atención que además de Presidente de la República Bolivariana de Venezuela, también se identifica en su cuenta como Hijo de Chávez, vínculo afectivo que le ha permitido conservar en la memoria colectiva el legado del fallecido presidente. Esta estrategia política y retórica ha sido muy bien explotada por el presidente Maduro desde su campaña electoral de 2013, pues, como señalan Aguillón, Marcano y Narváez (2015, p. 146), "la propuesta de Maduro estuvo centrada en la deificación de la imagen y el discurso del fallecido presidente Hugo Chávez”. Por su parte, Cabello se declara en su perfil de Twitter como chavista radical, calificativo que, tal como lo señala la periodista Parra (2016) en el portal Versión Final, es atribuido por él mismo, pues obedece al manejo de su liderazgo y al constante uso de un discurso encendido para la confrontación con la oposición. Se le considera uno de los hombres 
con mayor peso político dentro de la línea de mando del chavismo y de la alta jerarquía del actual Gobierno venezolano de Nicolás Maduro.

En cuanto al número de seguidores, el cuadro destaca que Henrique Capriles seguido de María Corina Machado, en representación de la coalición opositora al Gobierno, registran el mayor número de seguidores en sus cuentas; mientras que, por el sector oficialista, Nicolás Maduro se ubica en la primera posición, y luego aparece Diosdado Cabello. En consonancia con estos resultados, el portal web Twven.com (2016) confirma que Henrique Capriles se encuentra en la segunda posición del ranking de los 50 tuiteros de Venezuela con más seguidores (7.315.298) y el número uno en la categoría política, mientras que María Corina Machado se ubica en la posición 12 (4.399.291) y en el tercer puesto de la categoría política. En tanto, por el sector oficialista, el presidente Nicolás Maduro aparece en la posición 17 y el número dos en la categoría gobierno (3.354.860), y Diosdado Cabello se ubica en la posición 40 (2.223.595). Un dato que se debe destacar es que de acuerdo al estudio anual Twiplomacy de la consultora internacional Burson-Marsteller (2016 citado por Emol, 2016), el presidente de Venezuela, Nicolás Maduro, figura como el cuarto líder mundial con mayor influencia en Twitter; aparece además como el segundo líder con mayor cantidad de menciones en esta red social.

En las cuentas seleccionadas, resalta también un aspecto coincidente, excepto en la de Diosdado Cabello, que es la utilización de la insignia con el visto bueno azul, ubicada al lado derecho de sus nombres, que sirve para verificar la autenticidad de las cuentas que son de interés público. El hecho de implementar este sistema evita la falsificación y confirma su identidad de personaje político relevante, donde todos los tuits e informaciones publicadas deben ser de dominio público.

\section{¿Sobre qué temas hablaron los políticos?}

Un aspecto fundamental del enfoque lingüístico-discursivo es identificar los temas o tópicos más relevantes del discurso, con sus respectivas frecuencias de aparición (F), que en el caso de Twitter, surgen de las etiquetas y palabras clave extraídas de los tuits escritos por los actores políticos venezolanos. La tabla 2 presenta los tres principales temas o tópicos por cada mes, que de alguna manera permiten visualizar cuál fue la percepción que tuvieron los dirigentes políticos, tanto de la oposición como del oficialismo, acerca de la situación país que caracterizó a Venezuela durante el lapso correspondiente al tercer trimestre de 2016.

TABLA 2

Temas o tópicos más resaltantes en Twitter

\begin{tabular}{|c|c|c|c|c|}
\hline \multirow[b]{2}{*}{ Meses } & \multicolumn{4}{|c|}{ Temas o tópicos } \\
\hline & Oposición & $\mathrm{F}$ & Oficialismo & $\mathrm{F}$ \\
\hline \multirow{3}{*}{ Julio } & - Solicitud de referendo revocatorio & 30 & - Valores independendistas & 6 \\
\hline & - Ataques y críticas al gobierno & 13 & - Defensa de ideales revolucionarios & 5 \\
\hline & - Hambre y desabastecimiento & 9 & - Promoción de gestión gubernamental & 4 \\
\hline \multirow{4}{*}{ Agosto } & - Ataques y críticas al Gobierno & 28 & - Juegos Olímpicos & 10 \\
\hline & - Convocatoria de marcha a Caracas para exigir & & - Ataques a la oposición & 8 \\
\hline & referendo & 22 & - Promoción de gestión gubernamental & 5 \\
\hline & -Desobediencia civil & 14 & & \\
\hline \multirow{3}{*}{ Septiembre } & -Ataques y críticas al Gobierno & 22 & - Defensa de la paz y soberanía & 7 \\
\hline & -Toma de Caracas para solicitar referendo & 21 & - Ataques y críticas al gobierno & 6 \\
\hline & - Lucha y conquista por la libertad democrática & 12 & - Defensa de ideales revolucionarios & 5 \\
\hline
\end{tabular}


En la tabla se destaca que el discurso político de los líderes opositores estuvo sustentado en la "Solicitud del referendo revocatorio" y "Ataques y crítica al Gobierno", temas que además de presentar la mayor frecuencia de aparición, se mantuvieron recurrentes durante el periodo previsto del análisis. En estos dos tópicos, Henrique Capriles aparece como su principal propulsor al registrar el mayor número de mensajes, entre ellos se citan: “@hcapriles: Vamos por el paso que falta para el \#Revocatorio. Empezamos en el \#Zulia esta nueva cruzada \#VamosPorEl20”, “@hcapriles: Exijamos todos a las Sras del CNE respeten Constitución y fecha para 20\% Venezuela quiere \#Revocatorio2016”.

Ahora bien, la suspensión del referendo revocatorio en contra del presidente Nicolás Maduro por el Consejo Nacional Electoral (CNE), representó el evento político a partir del cual se desencadenó una serie de reacciones discursivas que los dirigentes adversos al Gobierno dejaron plasmadas, utilizando Twitter como plataforma comunicacional para convocar la participación ciudadana en la protesta nacional y, al mismo tiempo, encender el debate en la opinión pública con temas polémicos como "Convocatoria de marcha y Toma de Caracas", "Llamado a la desobediencia civil", mediante la activación del artículo 350 de la actual Carta Magna y la "Lucha y conquista por la libertad democrática"; estos dos últimos fueron liderados en la red mediante los tuits escritos por la coordinadora nacional de Vente Venezuela, María Corina Machado.

De sus cuentas se pueden extraer como ejemplos: “@hcapriles: Nuestro pueblo no acepta más retardos: REVOCATORIO será en 2016! Todos juntos, convocamos a \#MarchaACaracas el 1 de septiembre!”, “@MariaCorinaYa: Se acerca de modo inexorable el momento de convocar al pueblo a ejercer la legítima desobediencia civil generalizada”, “@MariaCorinaYa: Venezolanos, hoy nos encontramos en la calle con fuerza y civismo. Una nación que nació para ser libre; ciudadanos que conquistan la Libertad”.

Por otro lado, al observar la columna del sector oficialista pueden apreciarse los temas o tópicos con las mayores frecuencias, los cuales, algunos de ellos, se presentaron de manera recurrente, siendo promovidos principalmente por Nicolás Maduro, entre ellos "Promoción de gestión gubernamental" y "Defensa de ideales revolucionarios". En este sentido, se puede afirmar que el Jefe de Estado tiende a reforzar los mensajes que ya habían sido transmitidos por los medios masivos de información, utilizando para ello el Twitter como plataforma comunicacional alternativa para mantener informados a sus seguidores, de manera más directa y en tiempo real, acerca de la ejecución de sus programas de Gobierno, como se evidencia en el tuit: “@NicolasMaduro: Hoy estaré activando el planCambalache para sustituir aires acondicionados por equipos ahorradores y seguir avanzando en el Ahorro Eléctrico".

En la tabla pueden detallarse otros temas que, para el periodo seleccionado, ocuparon la atención de la opinión pública venezolana, tanto en el ámbito deportivo como en el contexto político: "Juegos olímpicos", "Ataques a la oposición" y "Defensa de la paz y soberanía". El primero tiene nuevamente a Nicolás Maduro como su principal propulsor, y hace referencia a los mensajes donde se destaca la participación y actuación de los atletas venezolanos durante los Juegos Olímpicos de Río de Janeiro (Brasil) 2016: “@NicolasMaduro: Una gran ovación le regalaron a nuestr@s Atletas en el StadiumOlímpicodeRío...Gracias Brasil Somos Pueblos Hermanos".

En la segunda temática, aparece Diosdado Cabello con la mayor frecuencia de tuits, y connota la actuación discursiva de los representantes del Alto Gobierno en torno a los ataques generados por la oposición, tras la suspensión del referendo revocatorio, evento que acentuó la confrontación política y la crisis institucional en Venezuela. Como ejemplo de esta situación, se menciona el tuit: “@dcabellor: Se lo venimos diciendo desde hace mucho tiempo, era imposible hacer un RR en el 2016, la dirigencia opositora le mintió otra vez a su gente". En contraste con esta postura aguerrida, se presenta el tercer tópico en el que líderes del gobierno, principalmente Nicolás Maduro y Jorge Arreaza, emitieron mensajes tendientes a fomentar un clima de pacificación nacional, así como a propiciar los valores de patriotismo y libertad que sustentan el proyecto político socialista: “@NicolasMaduro: Ha triunfado La Paz y la Vida...Hemos Vencido el odio fascista y al Golpismo...Gracias Patria Amada...Gracias Caracas”. 


\section{Uso del léxico como evidencia lingüística de los actores políticos}

Una vez precisados los temas o tópicos que subyacen de los textos y siguiendo los esquemas de los modelos de análisis, el nivel lingüístico establece la relevancia que tiene el estudio del léxico como evidencias lingüísticas que aporta el discurso (Molero de Cabeza y Cabeza, 2006). En este aspecto, con el levantamiento de los campos semánticos se pudo determinar el uso del lenguaje que hicieron los actores políticos en la construcción de su propia identidad discursiva, la de su práctica política y, sobre todo, fijaron sus criterios en torno a cómo describieron con sus palabras la visión de la realidad venezolana.

En el caso de los actores vinculados a la tendencia opositora, en la tabla 3 se pueden observar las lexías asociadas que conforman los principales campos semánticos, entre ellos "Hambre y escasez", "Referendo revocatorio", "Críticas al Gobierno" y "Protesta popular", donde se pone de manifiesto la postura crítica y controversial que asumen estos dirigentes políticos.

TABLA 3

Campos léxico-semánticos de dirigentes políticos opositores

\begin{tabular}{ll}
\hline Campos semánticos & \multicolumn{1}{c}{ Lexías asociadas } \\
\hline Hambre y escasez & $\begin{array}{l}\text { País hambriento, presos del hambre, protesta por comida, culpables del } \\
\text { hambre, detenidos por hambre, el hambre no espera, tiempo de } \\
\text { hambre, muriendo de hambre, pasar hambre, voces del hambre, } \\
\text { hambre y represión, revoquemos el hambre, en el país falta comida, } \\
\text { niños pasan hambre, crisis humanitaria, falta de medicina, lo que tengo } \\
\text { es agua y luz en mi nevera, el peor mes del desabastecimiento... }\end{array}$ \\
\hline Referendo & Cambio de gobierno, vamos por el 20\%, los revocaremos, revocar al \\
revocatorio & gobierno, tengamos patria con el revocatorio, revoquemos el hambre y \\
& la escasez, lucha, asamblea por el revocatorio, Venezuela quiere cambio, \\
& Venezuela quiere revocatorio, el revocatorio es un mandato, vía \\
& pacífica pa atajar el caos... \\
\hline Críticas al Gobierno & $\begin{array}{l}\text { Maduro, cúpula madurista corrupta, gobierno más corrupto de la } \\
\text { y oficialismo }\end{array}$ \\
historia, régimen, Maduro y Zapatero, la nueva estafa madurista, \\
tragedia venezolana, gobierno corrupto, destructor, antipatriótico, \\
criminal, con Maduro no hay futuro, se caen las caretas, trampa, \\
fraude, chantaje, Samper y Zapatero, los motores de Maduro, capos del \\
régimen, Maduro y su derroche, gobierno que no respeta sufragio, \\
magistrado chimbo, la enchufada...
\end{tabular}


Entre los adjetivos negativos, se mencionan "país hambriento", "presos del hambre", "culpables del hambre", "falta de medicina", "revocar al gobierno", "Venezuela quiere referendo", "la nueva estafa madurista", "tragedia venezolana”, "Venezuela se rebela”, “cacerolazo", “violan la Constitución”. Esta diversidad de términos tiende a cuestionar las políticas gubernamentales, visibilizar a los responsables del deterioro socioeconómico que afecta a los venezolanos, así como llamar la atención de la opinión pública acerca de la actitud asumida por el Gobierno y las instituciones oficiales respecto a las medidas asumidas en contra del referendo revocatorio, como el evento político más importante al cual se circunscriben la mayor parte de los textos difundidos en sus cuentas de Twitter.

Se puede observar que solo el campo semántico "Expresiones afectivas" contiene lexías positivas dirigidas a acentuar los vínculos con sus seguidores, mediante la difusión de expresiones como "amado Zulia", "un gran abrazo", "Dios los bendiga", "mi noble pueblo", "querida gente"; ellas enfatizan el trato afable y muestras de cariño cónsonos a los intereses de adhesión que, de manera sutil, quieren promover los dirigentes políticos.

La tabla 4 recoge los campos semánticos más relevantes con sus respectivas lexías asociadas que delataron el comportamiento lingüístico asumido por los tres líderes del oficialismo. En los campos denominados "Patria", "Gestión gubernamental", "Valores independentistas y revolucionarios" y "Paz", se evidencia un mayor número de lexías positivas usadas por personajes del Alto Gobierno venezolano, enfocadas, por un lado, a mitigar el discurso controversial en su contra y hacia las políticas gubernamentales que durante el periodo analizado generó la otra corriente política y, por el otro, legitimar entre sus seguidores las bondades del proyecto político socialista del siglo XXI. Entre las expresiones utilizadas, se citan: "Tiempos de siembra”, "defender nuestra independencia", "Moral en alto por la Patria", "Patria independiente", "consolidando misiones", "puerta de la paz", "sigamos venciendo", "con alegría y en Paz". De la misma forma, se comprobó, pero en menor grado, el empleo de lexías con cargas negativas dirigidas a descalificar a sus adversarios políticos de la oposición. Algunos ejemplos fueron: "golpe", "odio fascista", "sin imperio ni capataces", "arremetida fascista de la derecha", "lo peor de la vieja política", "triste final". 
TABLA 4

Campos léxico-semánticos de dirigentes políticos oficialistas

\begin{tabular}{|c|c|}
\hline Campos semánticos & Lexías asociadas \\
\hline Patria & $\begin{array}{l}\text { Patria independiente y bolivariana, celebrando la patria, Patria libre, } \\
\text { soberana, independiente, Patria solidaria, unión cívico-militar, Patria } \\
\text { en Bolívar y Chávez, Moral en alto por la Patria, quienes aman a su } \\
\text { patria, la FANB es patria, Patria grande, Patria amada, alegría y } \\
\text { energía, llano de la Patria, tiempos de siembra, Congreso de la Patria... }\end{array}$ \\
\hline $\begin{array}{l}\text { Gestión } \\
\text { gubernamental }\end{array}$ & $\begin{array}{l}\text { Consolidando misiones, nueva etapa segura del Plan de Taxis, } \\
\text { activando el plan cambalache... }\end{array}$ \\
\hline $\begin{array}{l}\text { Valores } \\
\text { independentistas y } \\
\text { revolucionarios }\end{array}$ & $\begin{array}{l}\text { Lucha por la verdadera y definitiva independencia, nuestra } \\
\text { independencia, defender nuestra independencia, fuerza de la historia, } \\
\text { sigamos venciendo, Mártir revolucionario, perseveremos y } \\
\text { venceremos, linda puerta de la Independencia, de la Soberanía, de la } \\
\text { libertad, de la Revolución... }\end{array}$ \\
\hline $\mathrm{Paz}$ & $\begin{array}{l}\text { Triunfando la paz y la vida, soberano en paz, puerta de la paz, con } \\
\text { alegría y en paz, derecho a la paz, paz social, cumbre de paz, cumbre } \\
\text { histórica de paz, justicia y paz, ser libre y vivir en paz... }\end{array}$ \\
\hline Críticas a la oposición & $\begin{array}{l}\text { Sin imperio ni capataces, el pasado y la soledad, arremetida fascista de } \\
\text { la derecha, odio fascista, golpismo, golpe, violencia, triste final, } \\
\text { crímenes, lo peor de la vieja política, desaparecidos, la bancada de la } \\
\text { derecha, agresión del imperio y sus lacayos, imperio norteamericano... }\end{array}$ \\
\hline
\end{tabular}

Fuente: elaboración propia

El hallazgo de todas estas lexías permite determinar la presencia de un proceso de sobrelexicalización o proliferación de términos (Molero de Cabeza y Cabeza, 2006, 2009), utilizados por los actores políticos venezolanos para establecer con el uso de la palabra su propia visión, que para el lapso estudiado caracterizó la situación país de Venezuela. El levantamiento de los campos semánticos arrojó que fueron los líderes políticos de la oposición, específicamente Henrique Capriles y María Corina Machado, quienes utilizaron la mayor provisión de sinónimos o cuasisinónimos para visibilizar un comportamiento del lenguaje cargado de términos negativos, destinado a construir su conceptualización de la crisis venezolana y deslegitimar a sus adversarios. Este mismo fenómeno lingüístico pudo observarse en menor medida del lado oficialista, donde Nicolás Maduro y Diosdado Cabello figuran como los principales actores, que a diferencia del otro sector político, expresaron mayor provisión de términos positivos para legitimar sus actuaciones políticas y las del propio Gobierno.

\section{Acciones lingüísticas emitidas por los actores políticos}

En este apartado, se estudian los actos de habla o actos lingüísticos como aspecto fundamental del componente pragmático, categoría que recoge las acciones en forma de creencias, opiniones y evaluaciones formuladas por los dirigentes políticos acerca de la situación país.

El uso del lenguaje lleva implícita la fuerza ilocutiva que marcan las diversas acciones intencionales que con mayor frecuencia fueron enunciadas en los textos escritos por los actores políticos durante el periodo de estudio. De este modo, la tabla 5 recoge los ocho actos de habla con sus frecuencias de aparición más 
representativas de este discurso, donde puede determinarse un repertorio muy variado de acciones ejercidas por los políticos: hacen aseveraciones, insultan, agradecen, preguntan y felicitan, entre otras.

TABLA 5

Actos de habla de los dirigentes políticos

\begin{tabular}{ccc}
\hline Actos de habla & Oposición & Oficialismo \\
\hline Aseverar & 219 & 47 \\
\hline Insultar & 25 & 7 \\
\hline Agradecer & 16 & 8 \\
\hline Preguntar & 7 & - \\
\hline Felicitar & 7 & 4 \\
\hline Exigir & 6 & - \\
\hline Denunciar & 4 & - \\
\hline Advertir & 1 & 2 \\
\hline
\end{tabular}

Fuente: elaboración propia

El hecho de que las aseveraciones registren la mayor frecuencia de ejecución demuestra que el mensaje de los políticos estuvo enfocado a emitir opiniones, comentarios y afirmaciones enfáticas vinculadas con los temas o tópicos destacados, que ya fueron mencionados en el apartado anterior. Algunos ejemplos de este acto de habla asertivo son: “@MariaCorinaYA: Esta es la Venezuela que se rebela; ciudadanos q asumimos q la nuestra es una lucha ética y q por eso, vamos a ganar"; “@hcapriles: Un DIÁLOGO en la situación que vive el país pasa necesariamente por los propios venezolanos!..., “@NicolasMaduro: Solo nosotros podemos superar las dificultades y avanzar hacia nuevos horizontes de la Revolución Bolivariana, en Unión CívicoMilitar Popular".

La efervescencia del discurso se manifiesta en el insulto que se profieren los actores políticos de ambas tendencias, el cual aparece como el segundo acto de habla que más se repite. En este sentido, el análisis deja en evidencia el uso de Twitter como herramienta comunicativa para propiciar desde esta red mensajes ofensivos y acusaciones que ponen en riesgo la credibilidad de los gobernantes e instituciones del Estado y, sobre todo, debilitan la calidad del debate político.

“@hcapriles: El Ministro del Interior preocupado por los “drones” y debería es ocuparse de los "la-drones"! Que Gobierno tan inepto!”, “@hramosallup: La comadre mayor dio ayer una rueda de prensa sin periodistas en el CNE”, “@dcabellor: El imperio norteamericano saca sus garras y asume el control del golpe de estado ante la ineptitud de sus lacayos. Los volveremos a derrotar”. Más allá de estos ejemplos, para Padilla (2015), el acto de insultar constituye un recurso muy utilizado en el discurso político para desacreditar al adversario; de allí que "para destruir la imagen del contrincante se recurre, en ocasiones, al insulto explícito" (p. 424). Además, constituye una estrategia política que profundiza la polarización, interrumpe y destruye el diálogo democrático (Bolívar, 2008).

El tercer acto de habla con más recurrencia en la interacción discursiva de los líderes políticos es el agradecimiento. Las muestras de afecto y gratitud publicadas en los tuits se corresponden con el gesto de cortesía que implementan los políticos como estrategia discursiva, con miras a reforzar su imagen positiva a través de la red y, al mismo tiempo, estrechar vínculos de cercanía con sus seguidores, expresada en algunos casos de manera colectiva, tal como se refleja en los ejemplos: “@hcapriles: Unidos vamos por buen 
camino. Gracias a nuestro pueblo del \#Zulia \#VzlaPorEl20”, “@hramosallup: Gracias Coro, tengan esperanza q saldremos de esta tragedia. Vzla tiene todo para hacerlo bien! \#SiHayFuturo”, “@NicolasMaduro: Ha triunfado la Paz y la Vida...Hemos vencido al odio fascista y al Golpismo...Gracias Patria Amada...Gracias Caracas".

En definitiva, al enmarcar cada una de las acciones dentro de las tipologías de los actos de habla puede precisarse que la mayor frecuencia se ubicó en los asertivos, destacándose las aseveraciones formuladas por los actores políticos; siguieron los expresivos que se manifestaron mediante los insultos, agradecimientos y felicitaciones. Prosiguieron los de tipo directivo, puesto que en este caso la intencionalidad del emisor fue influir en el hacer discursivo del otro, mediante un llamado de atención en forma de preguntas, exigencias, advertencias y denuncias, dirigido a los líderes del sector opuesto sobre los diversos eventos planteados en sus mensajes.

\section{Consideraciones finales}

Los esquemas aplicados en el análisis discursivo desde la perspectiva lingüístico-discursiva revelaron algunas características del comportamiento del lenguaje asumido por líderes políticos venezolanos en la producción de mensajes (tuits) en sus cuentas de Twitter.

- Los actores políticos venezolanos que registraron la mayor interacción discursiva fueron los representantes opositores Henrique Capriles (122 tuits) y María Corina Machado (92). El uso frecuente de Twitter hecho por estos líderes parece estar vinculado con la cantidad de seguidores que allí ostentan, donde la postura crítica que suscitaron desde sus mensajes confirmó su identidad en esta plataforma virtual como voces disidentes del Gobierno. En tanto, por el sector oficialista, pudo comprobarse que Diosdado Cabello (24) y Nicolás Maduro (23), mantuvieron una actividad más pasiva por la menor cantidad de tuits (mensajes) emitidos durante el periodo de estudio; no obstante, su discurso estuvo dirigido más a promover la pacificación y la convivencia social.

- El repertorio lexical con adjetivaciones negativas por parte de los dirigentes de la oposición, así como las acciones lingüísticas ejecutadas en sus tuits, reafirman su intrínseco propósito comunicativo de cuestionar la crisis socioeconómica y política venezolana en todas sus dimensiones. En este sentido, la actividad discursiva de mayor recurrencia a través de esta herramienta política se focalizó en visibilizar el eje temático de la solicitud del referendo revocatorio contra el mandato del presidente Nicolás Maduro. Por su parte, la estrategia lingüística oficialista se mantuvo circunscrita a mitigar el discurso de sus adversarios políticos, implementando actos y lexías positivas, centrados en resaltar el significado de Patria y los valores independentistas y revolucionarios como sus principales temas.

- En cuanto al uso político de la red, se pudo determinar que los dirigentes políticos seleccionados favorecen la circulación del mensaje más en forma unidireccional que fomentar la participación interactiva con sus seguidores y ciudadanía en general acerca de los mensajes que producen. Este manejo inadecuado de Twitter como plataforma comunicacional por parte de los líderes, más allá de establecer el acercamiento con su público, genera distanciamiento y mantiene a sus receptores en completa pasividad.

- El empleo de esta herramienta puso en evidencia la hegemonía comunicacional, acentuándose aún más en los actores políticos del oficialismo, quienes, además de hacer continuo uso de los medios masivos de información, abarcan otros espacios comunicacionales, entre ellos Twitter, con el fin de conseguir la adhesión del mayor número de seguidores en sus cuentas públicas, con miras a promover una imagen favorable de su gestión gubernamental y enfatizar sus ideales cónsonos a su proyecto político socialista del siglo XXI. 
- Por lo antes expuesto, puede determinarse que el comportamiento del lenguaje asumido por los actores políticos a través de Twitter estuvo definido por la exaltación de los rasgos de emotividad, por encima de los temas o tópicos que durante el periodo escogido determinaron la agenda del debate público. Los tuits revelaron además las discrepancias ideológicas bien marcadas entre los líderes pertenecientes a las dos tendencias políticas, lo cual implica que, más allá de propiciar el diálogo de paz y lograr el entendimiento nacional como propuesta gubernamental, la intencionalidad comunicativa de su discurso político estuvo circunscrita a encender la controversia verbal que acentuó la diatriba y radicalizó la polarización en el contexto político venezolano.

\section{Referencias}

Aguillón, P., Marcano, J., y Narváez, J. (2015). Deificación de Chávez y futuro país como soportes temáticos de la campaña presidencial venezolana de 2013. Revista Ethos Venezolana, 7(2), 146-161.

Bolívar, A. (2008). "Cachorro de imperio" versus "Cachorro de Fidel": los insultos en la política latinoamericana. Discurso \& Sociedad, 2(1), 1-38. Recuperado de http://www.dissoc.org/ediciones/v02n01/DS2\%281\%29Boli var.html

Calsamiglia, H., y Tusón, A. (1999). Las cosas del decir. Manual de análisis del discurso. Barcelona: Ariel.

Emol. Tecnología. (2016, 1.o de junio). Gobiernos latinoamericanos son los más activos en la red social Twitter [en línea]. Recuperado de http://www.emol.com/noticias/Tecnologia/2016/06/01/805543/Gobiernos-latinoam ericanos-son-los-mas-activos-en-la-red-social-Twitter.html

Lara, T. (2012, 11 de marzo). Twitter y sus funciones comunicativas [Artículo en un blog]. Recuperado de http://tis car.com/2012/03/11/twitter-y-sus-funciones-comunicativas/

Mancera Rueda, A., y Pano Alamán, A. (2013). Nuevas dinámicas discursivas en la comunicación política en Twitter. Círculo de Lingüistica Aplicada a la Comunicación, 56, 53-80. https://doi.org/10.5209/rev_CLAC.2013.v56.4 3867

Martínez Martín, M. (2012). Redes sociales y politica 2.0: Presencia en Twitter de los candidatos a las elecciones andaluzas de 2012 (Tesis de maestría inédita). Universidad de Sevilla, España. Recuperado de https://idus.us.es/xmlui/ handle/11441/25473

Mazzuchino, M. G. (2017). Twitter como espacio (¿anti?) político: análisis discursivo de los tuits del presidente Mauricio Macri. Revista Latinoamericana de Estudios del Discurso, 17(2), 65-82. Recuperado de https://raled.c omunidadaled.org/index.php/raled/article/view/247/248

Molero de Cabeza, L., y Cabeza, J. (2006). El análisis del discurso como método para la investigación en las ciencias humanas y sociales. En L. Molero de Cabeza y M. P. López (eds.), El análisis del discurso en las ciencias humanas $y$ sociales (pp. 13-42). Maracaibo, VE: LUZ- PDVSA.

Molero de Cabeza, L., y Cabeza, J. (2009). El poder, el querer y el protestar. Análisis sociolingüistico del discurso. Maracaibo, VE: Vicerrectorado Académico de la Universidad de Zulia.

Padilla, M. (2015). La argumentación política en Twitter. Discurso \& Sociedad, 9(4), 419-444. Recuperado de http:/ /www.dissoc.org/ediciones/v09n04/DS9(4)Padilla.pdf

Parra, M. (2016, 7 de agosto). Diosdado Cabello ejerce rol de jerarca entre los más radicales del chavismo. Versión final [en línea]. Recuperado de http://versionfinal.com.ve/politica-dinero/diosdado-cabello-ejerce-rol-de-jerarca-en tre-los-mas-radicales-del-chavismo/

Pottier, B. (1992). Teoría y análisis en lingüistica. Madrid: Gredos.

Romero-Castillo, E. (2016, 8 de septiembre). La crisis venezolana III (JUL - SEP 2016). DW Made for minds [en línea]. Recuperado de http://www.dw.com/es/la-crisis-venezolana-iii-jul-sep-2016/a-19536792

twven.com. Twitteros en Venezuela. (2016). Ranking de twitteros más seguidos en Venezuela (1 al 50) \#twven. Recuperado de http://twven.com/r/top-50/ 
Van Dijk, T. (1999). Ideología. Barcelona: Gedisa.

Van Dijk, T. (2008). Semántica del discurso e ideología. Discurso \& Sociedad, 2(1), 201-261. Recuperado de http://w ww.dissoc.org/ediciones/v02n01/20Dijk.pdf

Van Dijk, T. (2016). Estudios críticos del discurso: un enfoque sociocognitivo. Discurso \& Sociedad, 10(1), 137-162. Recuperado de http://www.dissoc.org/ediciones/v10n01/DS10\%281\%29Van\%20Dijk.html

Ventura, A. S. (2016). Argumentación y discurso político en Twitter. Análisis de la campaña presidencial Argentina 2011. Aposta. Revista de Ciencias Sociales, 69, 39-66. Recuperado de http://www.redalyc.org/articulo.oa?id=4 95952431003

\section{Notas}

* Artículo de investigación científica El artículo presenta los resultados del proyecto de investigación no subvencionado realizado por los autores bajo el título: “¿Es posible un diálogo de paz?: El comportamiento del lenguaje de líderes políticos venezolanos en Twitter”, registrado en el Consejo de Desarrollo Científico, Humanístico y Tecnológico de la Universidad del Zulia, bajo el número VAC-CONDES-CH-0524-16.

\section{Licencia Creative Commons CC BY 4.0}

Cómo citar este artículo: Aguillón Vale, P. D., y Narváez Serra, J. (2019). Comportamiento del lenguaje de líderes políticos venezolanos en el uso de Twitter. Signo y Pensamiento, 38(74). https://doi.org/10.11144/ Javeriana.syp38-74.cllp 